Editorial

\title{
Birth of AON
}

\author{
Anirban Biswas $^{1}$
}

${ }^{1}$ Vertigo and Deafness Clinic, Kolkata, West Bengal, India

Ann Otol Neurotol ISO 2018;1:1-2

As the Editor-in-Chief, I have been assigned the task of presenting a write-up that will be the vision statement of this new journal as well as the first editorial of the only official scientific publication of the Indian Society of Otology (ISO).

The ISO (indiansocietyofotology.com) is an established scientific society comprising more than 1,600 clinicians, academicians, researchers, and students involved in the practice of diagnostic and therapeutic otology. Currently, otology, as practiced in India, is comparable to the best in the world, and the volume of otologic work done in India is colossal and unmatched in any part of the globe. The discipline of otology has been nurtured, promoted, propagated, and carried to the remotest corners of the Indian subcontinent (not just India) by the relentless efforts of the ISO for the past quarter of a century. The society has single handedly catapulted the practice of otology in India to international standards. Drs K. K. Ramalingam, A. Mahadeviah, and P. G. Vishwanathan, and a few others who founded ISO 26 years ago for promoting and furthering otology in India were not only brilliant otologists but also outstanding teachers. No wonder, India today produces the best of otologists, and Indian otologists today are a pioneer in many therapeutic innovations in cosmetic otology, neurotology, endoscopic otology, medical audiology, oncology related to otology, cochlear implant programs, and other subspecialties of otology. Unfortunately, a lot of this excellence in otology attained by Indian otologists remains unknown, unexposed, and unrecognized. This is because there is no dedicated forum for publishing and disseminating the outcomes of the diagnostic and therapeutic modalities practiced by Indian otologists. This endeavor by the ISO is to fill in this gap, project, and promote the innovative and high-class work done here, and be a meeting point for sharing the experiences of Indian otologists with their international counterparts.

The purpose, in addition to the primary objective mentioned above, is to have a journal that will help practitioners in otology and postgraduate medical students in their daily clinical practice, keep them updated and abreast of the latest and the best of clinical methods, and assist them in lifelong learning. The objective is not merely to publish research articles related to otology but to help practicing otologists and postgraduate students in honing their skills, both clinical and otherwise. A clinical practitioner in supersensitive

Address for correspondence

Anirban Biswas, DLO, MBBS, Vertigo and Deafness Clinic, Kolkata 700091, West Bengal, India (e-mail: vertigodeafnesstinnitus@ gmail.com). super specialties, such as otology needs to master many skills-all of which are not necessarily med-

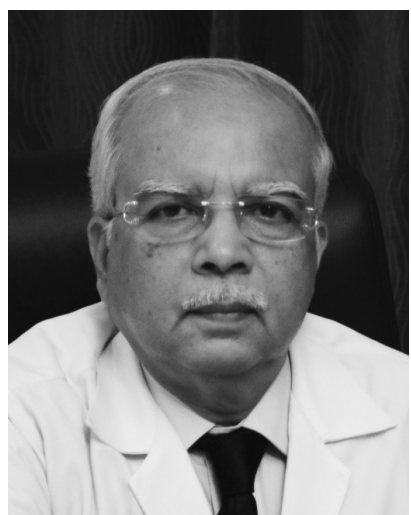

Dr. Anirban Biswas ical. Hence, the journal also needs to deliver information that will help them confront and tide over not just clinical problems (which is probably the easiest to tackle) but also aspects, such as medical ethics, legal issues, communication with patients and patient parties, practice management, psychological issues, basic statistics for easy publication of data, and the many other subjects that contemporary practitioners and even postgraduate students have to master for survival. The Annals of Otology and Neurotology (AON) intends to be an unparalleled source of advice (not mere information) for clinicians practicing in otology and be on the forefront for exchange of ideas, discussions, and arguments pertaining to the practice in otology in this part of the world.

As decided by the editorial board and the governing body of the ISO, AON will be a peer-reviewed journal with both print and online versions. Articles will be "open-access" in the online version and published once every 4 months. The journal invites articles from clinicians/scientific researchers in otology aspiring to be medical graduates in modern medicine. Related articles, such as those pertaining to medical ethics/research methodology/medicolegal issues, will be by invitation only. The journal will have original research articles, interesting case reports, a "How-I-Do-It" section, review articles, news, and a updated section for postgraduate students. The online version will have surgical and other otology-related videos.

Medical science is a dynamic philosophy, and our concepts keep on changing at a rapid pace with newer research findings pouring in by the hour from different parts of the world and also from the experience we gain from clinical practice. The journal will sieve the incoming information and selectively amplify (i.e., project) the most relevant inputs just as the cochlea does for our hearing. The journal will respond very appropriately to all clinical challenges (in the scientific perspective) faced by otologists in the practice of otology just like the vestibular labyrinth picks up any perturbations in our stability and brain responds by generating the measured corrective response to nullify the challenge.
Copyright (c) 2018 Indian Society of Otology
License terms

()(1) $\Theta \circledast$ https://doi.org/ 10.1055/s-0037-1608758 
All branches of otology have undergone mind-boggling advancements in the past few years. It is not possible for a practitioner to survive in clinical practice now without being constantly updated on the latest developments and practice guidelines. However, just being updated is not enough. No clinician is successful as a professional until he/she also delivers academically. In this profession, we wear two hats and are both teachers and students at the same time throughout our lives. Our professional standing depends on the academic work that we are doing, how we are taking the science forward and contributing to the upliftment of the discipline, how much knowledge/experience we are sharing among peers, and how much we are teaching/training our juniors. Professional success does not depend on the number of surgeries we perform or the number of patients that crowd our OPDs. These only can augment our financial status not our professional standing or peer appreciation. Hence, keeping up with the medical knowledge and academic contribution are a part and parcel of the medical profession. The journal is the platform for this aspect of otologic practice. It is wrong to think that only those in academic institutes can contribute academically. There are many examples where private practitioners, not even remotely connected to academic institutes, have contributed academically in a very big way. In fact, those in private practice who are completely on their own are in a much better position to perform academically as compared with those in the government teaching hospitals. They do not have any administrative constraints stifling their academic passions and can pursue their line of interest without hindrance from restrictive authorities or by overbearing bosses. They are also not packed off to godforsaken places on the pretext of "routine transfer" if they show their mettle and are on the verge of accomplishing some professional achievement.

An example of how medical science, especially otology is fast thrusting forward and changing our concepts completely can be understood by a related field, neurotology. In the past 10 years, neurotology has transformed from an occult science to a completely evidence-based medical discipline. Today, any disorder of the vestibular system can be diagnosed with utmost precision. So much of finesse has been achieved in diagnostic neurotology that the exact site of lesion, nature of pathology, and even the degree of impairment of the parts of the different organs in the vestibular system can be diagnosed accurately. Modern vestibulometry can tell us that the utricle of the right side is $58.67 \%$ impaired, the lateral semicircular canal of the left side is dysfunctional at high frequencies of vestibular stimulation, or that the inferior vestibular nerve of the left side is defective, or that there is a defect in the interstitial nucleus of Cajal in the upper midbrain as the oculomotor tests have shown a defect in vertical gaze. Today, we do not try to differentiate between a central and a peripheral lesion; the exact organ that is defective in the central or in the peripheral vestibular system is now accurately identifiable. Such broad demarcations are now a thing of the past. Treatment modalities have also undergone radical changes. When modern vestibulometry identifies that the utricle is defective, there are specific methods to stimulate utricular sensitivity and that exists for each and every part of the vestibular system. If the right anterior semicircular canal is defective or if the posterior canal of the left side is hypoactive, we can stimulate it specifically. The advancements in vestibulometry have led to matching advancements in therapeutics and specialized organ-targeted vestibular physiotherapy, and specific therapy for the underlying cause of the balance disorder is now a reality. The futility of the senseless, if not hazardous, practice of camouflaging the symptoms of vertigo by antivertigo drugs, which was prevalent even a few years back, has now been recognized and is today denounced and abhorred by the modern medical community. Until the otologist is aware of these developments, the management meted out to patients will be illogical and unscientific if not unethical and medicolegally untenable.

Such fundamental changes in our perspectives are taking place in every branch of otology. The success of a tympanoplasty operation is now not just to have an intact and properly taken-up graft; the purpose is to restore natural and normal hearing across all frequencies in three-dimensional space. Until the practitioners, especially those in the private sector (who do not have a protective institutional umbrella above their heads), are up-to-date with the latest and the best of diagnostic and therapeutic methodologies and still stick to the outdated and discarded practice methods, they are exposing themselves to mockery of their peers and ridicule by their clients and are also vulnerable in the court of law. The Annals of Otology and Neurotology is the endeavor of ISO to plug this loophole and serve the otologic community with an academic platform where members of the fraternity will present their experiences, showcase their research findings, and also learn from their peers in addition to updating themselves on all matters related to otology. 